\title{
The Effect of Acoustic Signalling on Male SPACING BEHAVIOUR IN THE SAGEBRUSH CRICKET: ARE SIGNALS USED IN TERRITORIAL DEFENSE?
}

\author{
W.A. SNEDDEN $\bullet$ ERINDALE COLLEGE \\ UNIVERSITY OF TORONTO $\bullet$ MISSISSAUGUA $\bullet$ ONTARIO \\ CANADA \\ S.K. SAKALUK $•$ ECOLOGY GROUP \\ DEPARTMENT OF BIOLOGICAL AND MEDICAL SCIENCES \\ ILLINOIS STATE UNIVERSITY \\ NORMAL
}

\section{$\rightarrow \quad$ ABSTRACT}

Acoustic signalling in orthopterans functions in mate attraction and/or intermale spacing. The pattern of intermale distances should reflect the degree to which signalling functions in territorial defense. Males who are unable to detect, and thus respond to, the signals of rivals should be at greater risk of inadvertently intruding on the territories of rivals and of being intruded upon.

We tested, in two field mark-recapture experiments with the sagebrush cricket Cyphoderris strepitans, the hypothesis that acoustic signals are used in intermale spacing, predicting that deafened males are compromised in their ability to repel rivals and should thus be found in closer proximity than control (hearing) males. There wás no difference in mating success between deaf and control groups. There was a difference in nearest-neighbor distance between deaf and control animals in one replicate of one experiment and in one night of one replicate of the other experiment. These results suggest that calling has a sporadic effect on spacing behaviour of sagebrush crickets and thus primarily functions in mate attraction.
The results are discussed in the context of the mating system of sagebrush crickets and the economics of territory defense.

\section{$\checkmark \quad$ INTRODUCTION}

Acoustic signalling in many ensiferan orthoptera functions to attract potential mates and in the defense and maintenance of territories (Cade 1979, Searcy \& Anderson 1986). Intermale conflict may often be resolved exclusively through acoustic signalling (Theile \& Bailey 1980, Shaw et al. 1982) and Bailey (1991) states that "fighting between male acoustic insects in nature is rare." However, in some species of acoustic orthoptera interactions between territorial males can escalate to physical combat (Alexander 1961, Morris 1971, Dixon \& Cade 1986, Simmons 1986). The overall cost of territory maintenance should be reduced in species where conflict is resolved through the mutual avoidance of signalling rivals (Alexander 1961, Davis \& Houston 1984).

Male sagebrush crickets, Cyphoderris strepitans, do not engage in overt aggression, even 
when in close proximity (Snedden \& Sakaluk 1992) but do appear to respond acoustically to calling rivals (pers. obser.). Signalling in sagebrush crickets has been shown to be an important component of male mating success; calling males obtain significantly more matings than experimentally muted males (Snedden \& Sakaluk 1992). This finding could result from the attraction of females by calling males or by the diminished territorial defense capacity of muted males. If acoustic signalling functions, in part, in territorial defense then muted males should have a reduced capacity to repel interlopers, especially at long range.

Territoriality should be reflected in intermale spacing; territorial males should maintain a minimum nearest-neighbor distance and thus exclusive broadcast area within which they have exclusive access to females. If calling functions in male spacing then males who are unable to detect the signals of rivals should be at greater risk of 1) interloping on the territory of rivals and 2) having rivals intrude on their territory. We tested the importance of male signalling to territoriality, as manifested in male spacing behaviour, in two markrecapture field experiments in which some males were rendered deaf. We predicted that deafened males would 1) have shorter nearest-neighbor distance and 2) move shorter distances to avoid risks.

\section{- METHODS}

This study was conducted during May and June 1993 in Grand Teton National Park, Wyoming, USA. Male sagebrush crickets were collected, at night, with the aid of headlamps, from sagebrush fields within the park. Only virgin males, as evidenced by intact hindwings (Morris et al. 1989, Sakaluk \& Snedden 1990) were used throughout the study. Animals were held at the University of Wyoming-National Park Service Research Center, approx. $30 \mathrm{~km}$ from the collection sites, in separate cages and supplied portions of apple for food. Experimental animals were rendered deaf by ablating the tympanic membranes on each foreleg with an insect pin. Subsequent recording from the auditory neuron (following the procedures of Mason 1991a, b) confirmed the efficacy of this technique. Control animals were handled in a similar manner and an insect pin was used to puncture the hind femora. All animals were individually identified by a numbered tag attached to the pronotum with cyanoacrylic glue. Fluorescent paint was applied to the pronotum and hind femora of all study animals to facilitate recapture using portable UV lights. In each experiment animals were recaptured following release and their position marked with a survey flag. Nearest-neighbor distance and distance moved since last recapture were measured using a Sonin ${ }^{\circledR} R$ ultrasonic measuring device. The natural distribution of males was determined at each site (see below) by marking the location of non-experimental males with a survey flag and subsequently measuring nearestneighbor distance.

Data were analyzed using the procedures of Systat ${ }^{\circledR}$.

\section{EXPERIMENT 1}

Two replicates of this experiment were conducted, one in a sagebrush field on a bench of the flood plain of the Snake River at Deadman's Bar (DMB) and the other in a sagebrush field adjacent to Pacific Creek (PC). In each replicate an area of approximately $13000 \mathrm{~m}^{2}$ was cleared of all calling males prior to the release of experimental animals. At DMB the field was cleared on the nights of May 15,17 , and 18 and at PC on the nights of June 1517. In each replicate animals were randomized as to date of capture and divided into two groups (deafened and control) and treated as described above. At approx. 2130 on 19 May (DMB) and June 18 (PC) the animals were released at two points, one experimental and one control, $40 \mathrm{~m}$ apart. Each release location was marked with a survey flag. Eighteen deaf and 19 control animals were released at DMB and 23 deaf and 24 controls at PC. On the nights of May 20 and 23 (DMB) and June 19 and 20 (PC) we recaptured males, marked their location with a survey flag, determine their mating status, and subsequently measured the distance to their nearestneighbor and distance moved since last recapture.

\section{EXPERIMENT 2}

Two areas $\left(13000 \mathrm{~m}^{2}\right) 65 \mathrm{~m}$ apart, of sagebrush field were cleared of males on May 25-28 (DMB) and June 9-11 (PC). At each location sagebrush plants were marked to establish a grid (control and experimental at each site) such that the nearest-distance represented a compressed distribution (interbush distance less than natural nearest-neighbor 
distance of crickets- see results). At 0800 on May 31 (DMB) and June 13 (PC) one male was released at the base of each marked bush. Thirty five deaf and 34 control animals were released at DMB and 29 deaf and 30 controls at PC. On the nights of May 31 and June 1 (DMB) and June 13-15 (PC) animals were recaptured, their mating status determined, and their position marked with a survey flag. Nearest-neighbor distances and distance moved since last recapture were determined as above.

\section{$\checkmark \quad$ RESUlts}

The natural nearest-neighbor distance at the site was; mean $=8.99 \mathrm{~m}, \mathrm{SD}=7.17$, range $=0.13$ -
30.87 and at the PC site; mean $=10.82 \mathrm{~m}, \mathrm{SD}=$ 8.99 , range $=0.88-38.28$. There was no difference in natural nearest-neighbor distance between the two sites (Mann-Whitney U, U $=872, \mathrm{p}=0.49$ ). Recapture and mating frequencies are in Table 1. Recapture frequency varied between $97 \%$ (34/35) and $63 \%(12 / 19)$. There was no difference in recapture frequency between deaf and control groups with replicates $\left(\mathrm{X}^{2}\right.$, all $\mathrm{p}>0.05$ : Bonferroni adjustment for sequential tests, Rice 1989). When all replicates were pooled, a greater proportion of deaf males were recaptured (Fisher's Exact test, $p=0.039$ ). There was no significant difference in mating frequencies between control and deafened animals $\left(\mathrm{X}^{2}\right.$, all $p>0.05$ ).

Table 1. Summary of recapture and mating frequencies by replicate for each experiment. There was no significant difference between deaf and control recapture frequencies within replicates (Chi-square all $p>0.05$ ) or matings frequencies (Fisher's exact all $\mathrm{p}>0.05$ ).

\begin{tabular}{||l|l|l|l|l|l|l||}
\hline \hline Experiment & \multicolumn{2}{|l|}{ \# Released } & \#Recaptured* & \multicolumn{2}{l||}{ \#Mated** } \\
\hline & Deaf & Control & Deaf & Control & Deaf & Control \\
\hline 1-DMB & 18 & 19 & 15 & 12 & 0 & 0 \\
\hline 1-PC & 23 & 24 & 17 & 22 & 2 & 0 \\
\hline 2-DMB & 35 & 24 & 24 & 26 & 9 & 8 \\
\hline 2-PC & 29 & 30 & 28 & 24 & 4 & 9 \\
\hline
\end{tabular}

DMB - Deadman's Bar site

PC - Pacific Creek site

* - total number recaptured over total survey nights

** - total number mated at end of experiment

\section{EXPERIMENT 1.}

There was no significant difference in nearest-neighbor distance or distance moved between deaf and controls on either recapture night at the DMB site (Mann-Whitney U, all p >0.05). There was a significant difference in nearest-neighbor distance and distance moved on the first recapture night at PC (Mann-Whitney U, U = 40, p = 0.001; U $=51, \mathrm{p}=0.003)$. There was a significant difference in distance moved on the second recapture night (Mann-Whitney U, U $=23.5, \mathrm{p}=0.02$ ) but no difference in nearest-neighbor distance (MannWhitney $U, U=62, p>0.05$ ). Median nearestneighbor distance vs. day of recapture for Experiment 1 are in Figure 1.

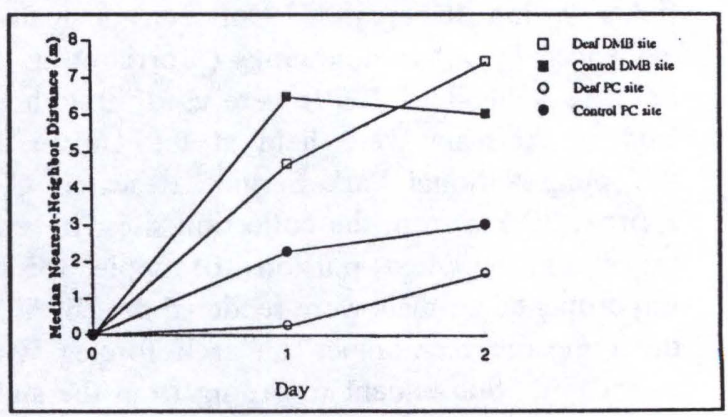

Figure 1. Median nearest-neighbor distance vs. day of recapture for Experiment 1. There was no significant difference in nearest-neighbor distance between deaf and control groups on either recapture night at the Deadman's Bar site (Mann-Whitney U, p $>0.05$ ). There was a significant difference in nearest-neighbor distance between deaf and control groups only on the first recapture night at the Pacific Creek site (Mann-Whitney $U, p=0.001$ ). DBM = Deanman's Bar site $\mathrm{PC}=$ Pacific Creek site. 
Table 2. Summary of nearest-neighbor distances (median and range) and distance moved (median and range) by replicate for each experiment.

\begin{tabular}{|c|c|c|c|c|c|c|c|}
\hline & & \multicolumn{3}{|c|}{ Nearest-Neighbor Distance (m) } & \multicolumn{3}{|c|}{ Distance Moved (m) } \\
\hline \multicolumn{2}{|c|}{ Experiment } & \multicolumn{3}{|c|}{ (median \& range) } & \multicolumn{3}{|c|}{ (median \& range) } \\
\hline & & Day 1 & Day 2 & Day 3 & Day 1 & Day 2 & Day 3 \\
\hline 1-DMB & $\begin{array}{l}\text { Deaf } \\
\text { Control }\end{array}$ & $\begin{array}{l}4.64(9.64) \\
6.48(5.40)\end{array}$ & $\begin{array}{l}7.42(20.75) \\
6.02(12.56)\end{array}$ & & $\begin{array}{l}11.33(26.06) \\
12.76(22.23)\end{array}$ & $\begin{array}{l}14.39(22.80 \\
8.25(21.57)\end{array}$ & \\
\hline 1-PC & $\begin{array}{l}\text { Deaf } \\
\text { Control }\end{array}$ & $\begin{array}{l}0.23(3.00) \\
2.28(5.18)\end{array}$ & $\begin{array}{l}1.69(26.25) \\
3.02(17.20\end{array}$ & & $\begin{array}{l}2.28(5.18) \\
2.95(3.56)\end{array}$ & $\begin{array}{l}3.83(28.37) \\
0.0(2.77)\end{array}$ & \\
\hline 2-DMB & $\begin{array}{l}\text { Deaf } \\
\text { Control }\end{array}$ & $\begin{array}{l}1.48(14.11) \\
3.13(10.25)\end{array}$ & $\begin{array}{l}2.90(5.97) \\
5.04(16.74)\end{array}$ & & $\begin{array}{l}2.17(17.54) \\
4.15(25.88)\end{array}$ & $\begin{array}{l}5.21(20.46) \\
10.39(32.03)\end{array}$ & \\
\hline 2-PC & $\begin{array}{l}\text { Deaf } \\
\text { Control }\end{array}$ & $\begin{array}{l}2.33(4.49) \\
2.73(3.75)\end{array}$ & $\begin{array}{l}2.04(7.51) \\
2.70(11.17)\end{array}$ & $\begin{array}{l}3.31(20.53) \\
3.33(10.74)\end{array}$ & $\begin{array}{l}0.0(8.7) \\
1.42(6.49)\end{array}$ & $\begin{array}{l}0.88(9.45) \\
1.28(12.82)\end{array}$ & $\begin{array}{l}6.62(40.53) \\
3.78(20.39)\end{array}$ \\
\hline
\end{tabular}

\section{EXPERIMENT 2}

There was no difference between deaf and control initial (grid) nearest-neighbor distances in either replicate ([DMB; ANOVA, $\mathrm{F}=0.15, \mathrm{p}$ $=0.70]$, [PC; ANOVA, $\mathrm{F}=0.88, \mathrm{p}=0.35])$. There was a significant difference in nearest-neighbor distance between deaf and control groups in Experiment 2 at DMB on both recapture nights ([night 1; Mann-Whitney $\mathrm{U}, \mathrm{U}=84.5, \mathrm{p}<0.001]$, [night 2; $U=128, p=0.002$ ]). There was no difference in distance moved between groups on either recapture night ([night 1; Mann-Whitney U, U $=189, \mathrm{p}=0.23$ ], [night 2; $\mathrm{U}=109, \mathrm{p}=0.15$ ]). There were no significant differences in nearestneighbor distances between control and deaf animals in Experiment 2 at PC (Mann-Whitney U, all $p>0.05$ ) or in distance moved (Mann-Whitney U, all $p>0.05$ ) on any of the three recapture nights. Median nearest-neighbor distance vs. day of recapture for Experiment 2 are in Figure 2.

\section{$\downarrow \quad$ DISCUSSION}

If territorial defense is mediated through acoustic signalling then males who are unable to detect and respond to the signals of rivals should be at risk of intruding on the territories of rivals and be intruded upon. Males who are unable to detect rivals should be found, on average, closer to competitors than males who can detect and respond to other callers. Several studies have shown the importance of acoustic signalling to male spacing in orthopterans

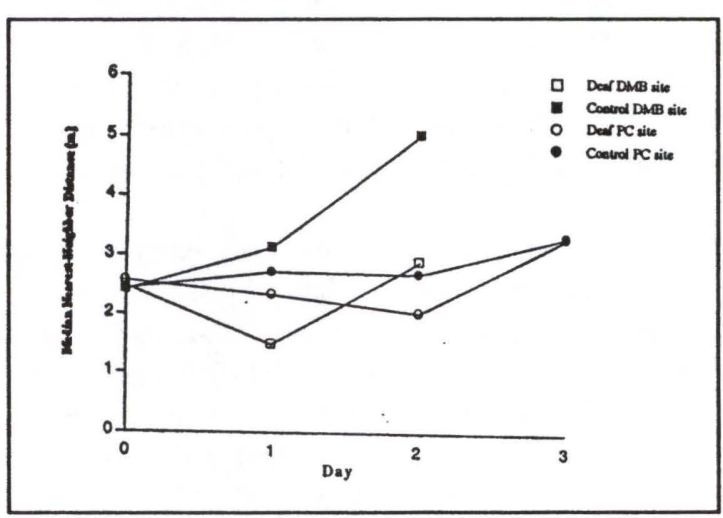

Figure 2. Median nearest-neighbor distance vs. day of recapture for Experiment 2. There was a significant difference in nearest-neighbor distance between deaf and control groups in both recapture nights at the Deadman's Bar site (Mann-Whitney U, $\mathrm{p}<0.05)$. There was no significant difference in nearest-neighbor distance between deaf and control groups on any of the three recapture nights at the Pacific Creek site (Mann-Whitney U, all p >0.05).

DBM $=$ Deadman's Bar site PC $=$ Pacific Creek site.

(Campbell \& Shipp 1979, Cade 1981, Arak et al. 1990, Hissmann 1991). If territorial maintenance is important to male mating success then males should respond aggressively to repel intruders from their territory. Males C. strepitans do not exhibit the overt aggressive behaviours (Snedden and Sakaluk 1992) typical of some orthopteran species (Morris 1971). Similarly, Simmons and Bailey (1993) 
reported that males of an undescribed species of zaprociline katydid "show no signs of overt aggression" but do however appear to use acoustic signalling to actively avoid one another.

The results of this study suggest that, in sagebrush crickets, the effect of calling on male spacing is variable and may represent mutual avoidance and not territorial defense per se. In Experiment 1, a significant difference between deaf and control groups in nearest-neighbor distance was found for only one night in one replicate. Experiment 2 showed a significant difference in nearest-neighbor distance in one replicate and not the other. There was no difference between groups in mating frequency suggesting that spacing, mediated through signalling, is not crucial to male mating success (although mating frequency was low across all treatments likely due to the short duration of the experiments). Jacobson (1993) also found no difference in mating frequency between deaf, shamoperated, and control male sagebrush crickets in a similar field experiment of longer duration.

Sagebrush crickets mate early in the spring, soon after snow melt, when nightly temperatures are typically below $10^{\circ} \mathrm{C}$ (Dodson et al. 1983, Sakaluk \& Snedden 1990, Snedden \& Sakaluk 1992). Acoustic signalling is energetically expensive, especially at such low temperatures (Walker 1975a, b, Prestwich \& Walker 1981, Dodson et al. 1983, Ryan 1988). Additionally, males provide females with a substantial nuptial "gift" in the form of the hindwings which are partially consumed by the female during copulation, as well as haemolymph ingested during wing-feeding and a large spermatophore consumed subsequent to copulation (Morris et al. 1989, Sakaluk \& Snedden 1990, Snedden \& Sakaluk 1992). On most nights during the breeding season males have only a few hours available when temperatures are suitable for calling. Time and energy spent in the aggressive defense of a calling perch, or in a take-over attempt of a rival's perch, are likely not to provide a reproductive payoff exceeding these costs.

The ambiguous effect of signalling on male spacing in $C$. strepitans may be a function of the mating system of this species and the potentially high cost of territorial defense. Males should defend territories only when the energetic costs of defense are exceeded by the benefits derived from maintaining a territory (Alexander 1961, Davis \&
Houston 1984). One important benefit of territoriality is the monopolization of available females and a resultant enhancement of mating success relative to non-territory holding individuals. For this benefit to be realized, territories must be economically defensible and provide access to a greater number of females than could be obtained outside the territory. The number of available territories, or at least potentially good ones, should thus be limiting. This does not seem to be the case with $C$. strepitans. Males call from perches in sagebrushes and perch sites do not appear to be limiting; the density of suitable calling perches is an order of magnitude higher than that of males.

The substantial energetic costs of attracting a mate (calling), securing a mating (nuptial feeding), and the high ratio of available perches to males are likely responsible for selection for mutual avoidance, mediated through acoustic signalling, as opposed to strict territoriality in this species.

\section{- ACKNOWLEDGEMENTS}

We thank H. Harlow for logistic support and stimulating discussion. J. Bon, C. Collis, B. Ende, and C. Lo assisted in the field. A. Mason conducted the neurological recordings to confirm the efficacy of the deafening technique. G. K. Morris suggested Experiment 1. I thank G. K. Morris, S. K. Sakaluk and M. Ritchie for comments on the manuscript. The research was supported by a grant from the UWNPS Research Center to S. K. S. and W. A. S. and an NSF grant to S. K. S. J. B. and C. L. were supported by an NAF REC grant to S. K. S.

\section{- Literature Cited}

Alexander, R. D. 1961. Aggressiveness, territoriality, and sexual behavior in field crickets Orthoptera:Gryllidae. Behaviour, $17,130-223$.

Arak, A., T. Eiriksson, T. Radesäter. 1990. The adaptive significance of acoustic spacing in male bushcrickets Tettigonia viridissima: a perturbation experiment. Behav. Ecol. Sociobiol., 26,1-7. 
Bailey, W. J. 1991. Acoustic Behaviour of Insects. Chapman and Hall, London. 225 pp.

Cade, W. H. 1981. Field cricket spacing, and the phonotaxis of crickets and parasitoid flies to clumped and isolated cricket songs. $\mathrm{Z}$. Tierpsycol., 55,365-375.

Cade, W. H. 1979. The evolution of alternative male reproductive strategies in field crickets. In: Blum, M. S., and Blum, N. A. (ed.), Sexual Selection and Reproductive Competition in Insects, Academic Press, New York, pp. 343-379.

Campbell, D. J. \& E. Shipp. 1979. Regulation of spacial patterns in populations of the field cricket Teleogryllus commodus (Walker). Z. Tierpsycol., 51, 260-268.

Davis, N. B., \& A. I. Houston. 1984. Territory economics. In: Krebs, J. B., and Davies, N. B. (ed.). Behaviourial ecology:an evolutionary approach, 2nd ed., Blackwell Scientific publications, Osvord, pp. 148-169.

Dixon, K. A., \& W. H. Cade. 1986. Some factors influencing male-male aggression in the field cricket Gryllus integer (time of day, age, weight and sexual maturity). Anim. Behav., 34, 340-346.

Dodson, G. N., G. K. Morris, \& D. T. Gwynne. 1983. Mating behavior of the primitive orthopteran genus Cyphoderris (Haglidae). In: Gwynne, D. T., and Morris, G. K. (ed.), Orthopteran Mating Systems:Sexual Competition in a Diverse Group of Insects, Westview Press, Boulder, pp. 305-318.

Hissmann, K. 1991. Phonotaxis of male cricket Gryllus campestris in a field population as an indication of territoriality (Orthopera:Gryllidae) J. Insect Behav., 4, 675-681.

Jacobson, K. A. 1993. MSc Thesis, Illinois State University, Normal, Illinois.

Mason, A. C. 1991a. MSc Thesis, University of Toronto, Toronto, Canada.
Mason, A. C. 1991b. Hearing in a primitive ensiferan: the auditory system of Cyphoderris monstrosa (Orthoptera: Haglidae). J. Comp. Physiol. A., 168,351363.

Morris, G. K. 1971. Aggression in male conocephaline grasshoppers (Tettigoniidae). Anim. Behav., 19,132-137.

Morris, G. K., D. T. Gwynne, De. E. Klimas, \& S. K. Sakaluk. 1989. Virgin male mating advantage in a primitive acoustic insect (Orthoptera: Haglidae). J. Insect Behav., 2,173-185.

Prestwich, K. N. \& T. J. Walker. 1981. Energetics of singing in crickets: effect of temperature in three trilling species (Orthoptera: Gryllidae). J. Comp. Physiol., 143,199212.

Rice, W. R. 1989. Analyzing tables of statistical test. Evolution, 43,223-225.

Ryan, M. J. 1988. Energy, calling and selection. Am. Zool., 28,885-898.

Sakaluk, S. K., \& W. A. Snedden. 1990. Nightly calling durations of male sagebrush crickets, Cyphoderris strepitans: size, mating and seasonal effects. Oikos, 57,153-160.

Searcy, W. A., \& M. Anderson. 1986. Sexual selection and the evolution of song. Ann. Rev. Ecol. Syst., 17,507-533.

Shaw, K. C., R. J. Bitzer, \& R. C. North. 1982. Spacing and movement of Neoconocephalus ensinger males (Conocephaline: Tettigoniidae). J. Kan. Ent. Soc., 55,581592.

Simmons, L. W. 1986. Inter-male competition and mating success in the field cricket, Gryllus bimaculatus (DeGeer). Anim. Behav., 34,567-579.

Simmons, L. W. \& W. J. Bailey. 1993. Agonistic communication between males of a zaprochiline katydid. (Orthoptera: Tettigoniidae). Behav. Ecol., 4,364-368. 
102

Snedden, W. A., \& S. K. Sakaluk. 1992. Acoustic signalling and its relation to male mating success in sagebrush crickets. Anim. Behav., 44,633-639.

Theile, D., \& W. J. Bailey. 1980. The function of sound in male spacing behaviour in bushcrickets (Tettigoniidae, Orthoptera). Aust. J. Ecol., 5,275-286.

Walker, T. J. 1975a. Effects of temperature, humidity, and age on stridulatory rates in Atlanticus spp. (Orthoptera: Tettigoniidae:Decticinae). Ann. Entomol. Soc. Amer., 68,607-611.

Walker, T. J. 1975b. Effects of temperature on rates in poikilotherm nervous systems: evidence from the calling songs of meadow katydids (Orthoptera: Tettigoniidae: Orchelimum) and reanalysis of published data. J. Comp. Physiol., 101,57-69. 